\title{
The proposal of the closure element pipe
}

\author{
Kamil Fojtášek ${ }^{1, a}$, Jaroslav Krutil $^{1}$ and Lukáš Dvořák ${ }^{1}$ \\ ${ }^{1}$ VŠB-Technical University of Ostrava, Faculty of Mechanical Engineering, Department of Hydrodynamics and \\ Hydraulic Equipment, 17. listopadu 15/2172, Ostrava 70833, Czech Republic
}

\begin{abstract}
The present paper summarizes the basic equations describing the behavior of butterfly valves during the fluid flow. Butterfly valves are used as a safety element in the energy industry, petrochemical industry, in steam lines etc. The paper describes the theoretical determination of the control torque on the closure element, the torque causes the opening and closing of butterfly valve. Determination of this torque depends on many factors, geometry of the closure element, misalignment to the axis of fluid flow, control method of valve, method of imposition of the moving member and of course on the operating parameters. Correct determination of the torque affects the proper design butterfly valves and ensure its functionality, which can prevent damage to other elements of the monitoring system.
\end{abstract}

\section{Introduction}

The armatures are a part of many devices in various industry sectors. Very often they ensure the safety and reliability of a much larger and more complex unit. The group of closing valves include various constructions of gate valves, shut-off valves, ball valves and butterfly valves. Their primary function is to ensure reliable opening and closing of the flow with a desired tightness, whereby is basically controlled the movement of the transported medium. Besides the already mentioned tightness, is in the choice of the closure element must be also take account an additional attributes such as: pressure loss in the flow of the transported media (usually they are characterized by loss coefficient), the inner diameter of the pipe and nominal working pressure, the size of actuating force, the possibility of control, constructional length of closure element, its durability and repairability.

Next we will devote the butterfly valves, the use of which has recently been significantly expanded. Butterfly valve has a small constructional length, weight and relatively small loss coefficient (hydraulic resistance). It consists of a valve body, rotatable circular plate, drive pin and elastic cuff seal. The functional principle is quite simple. The flow of transported medium is caused by the rotating of circular plate around its axis (up to 90 degrees). This is achieved by a drive pin, which is located in the middle of plate Fig.1 (left) or in off-axis of plate Fig.1 (right) (eccentric butterfly valves), depending on the construction of the valve. Tightness of valve is ensured by the elastic cuff seal. Cuff material is usually elastomer depending on the type of working medium. Operating pressures for simple valves are in the range $1 \div 2,5 \mathrm{MPa}$, temperatures to $130^{\circ} \mathrm{C}$ and the inner diameters $1500 \mathrm{~mm}$. Recommended velocity of transported media depends on the inner diameter of the valve. The permissible velocity for liquids is $3 \mathrm{~m} \cdot \mathrm{s}^{-1}$ and for gases $50 \mathrm{~m} \cdot \mathrm{s}^{-1}$, at valves with inner diameter up to $450 \mathrm{~mm}$. With increasing inner diameters of valves are reduced the permissible velocities. For maximal inner diameter of valve $1500 \mathrm{~mm}$ is recommended flow velocity for liquids only $1 \mathrm{~m} \cdot \mathrm{s}^{-1}$. The flow velocity of the working medium affects the desired control torque. Loss coefficient is featured for maximum inner diameter in range $\zeta(0,12 \div 0,25)$, for smaller diameters its value increases [1].
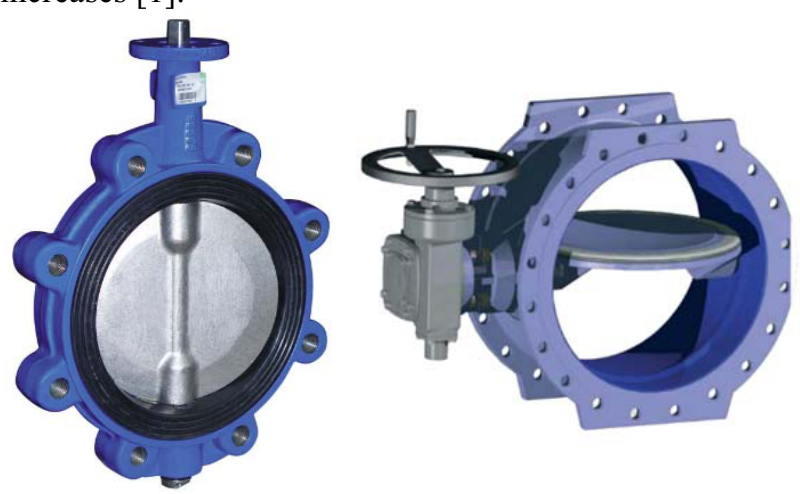

Fig. 1. Simple butterfly valve CEREX-L (left), Double eccentric butterfly valve EBRO (right)

At a simple valve and valve with eccentric fitting of plate occurs when they are closing to the deformation of the elastic sealing material. This fact must be included in the size of the control torque a negatively affects the size of working pressure. For this reason, there is used constructional variant of valves with double or triple eccentricity. In this construction there are inserted conical sealing surface of the plates in the conical sealing

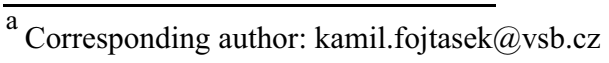


surfaces in the valve body. This modification allows the use of a metal spring elements and achieve higher operating pressures and temperatures. However, increases loss coefficient.

Constructionally very similar to butterfly valves are check valves. With check valves the main function is to ensure the flow of working medium in one direction only. In the other direction valve must prevent from flow. The function of these valves must be automatic and reliable. Usually they work as a fully open, which places emphasis on a low loss coefficient values. The valve disc is suspended on a lever which is pivotable about a pivot. For closing of valves acting torque, which is determined by the weight of plate and its length centre of gravity and the lever from the axis of rotation. This torque is increases with the opening angle of the plate. The opposite moment is deduced as the hydraulic force of the flowing medium. If the valve is fully open, the valve disc is located almost tangentially to the flow direction of working medium. For closing the valves is used primarily mechanical torque from the weight of plate. Hydraulic torque in reverse flow at closing mainly involved in the final phase of closing and causes rapid closing movement of the valve. An important factor is the time, for which the valve is closed. If the valve is closed fast enough, than it is possible to prevent a back-flow of the working medium. However, the rapid closure of valves may result in pressure surges. To prevent reverse flow and accelerate the closing of the plate can be used an external lever with mass weight. This weight may be sliding on the lever. Thereby can be regulate the closing moment and the resulting closing speed of valves, with regard to working conditions [5].

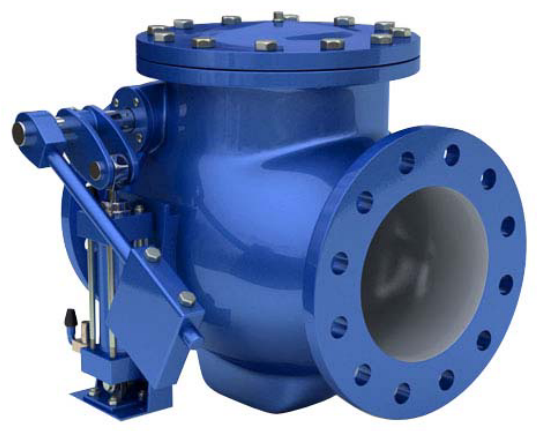

Fig. 2. Double eccentric check valve with mass weight and hydraulic motor APCO-CVS

Check valve can be complemented by external control Fig. 2, due to the character of the flow of the working medium and the function of valves in the circuit [6]. This control may be in the form of electric, pneumatic or hydraulic motor.

\section{Theoretical analysis of moments}

In this section will be described the theoretical determination of the control torque on closure element (butterfly valve), this torque causes the opening and closing of valve. In analysis is considered butterfly valve with double eccentricity, with external positionable weights on lever. Pivot is supported in bearings which are equipped with seals. Seals prevent leaks of working medium. Along the perimeter of the plate is placed gasket. For opening the valve (depending on the character of flow) is used a hydraulic motor Fig.3.

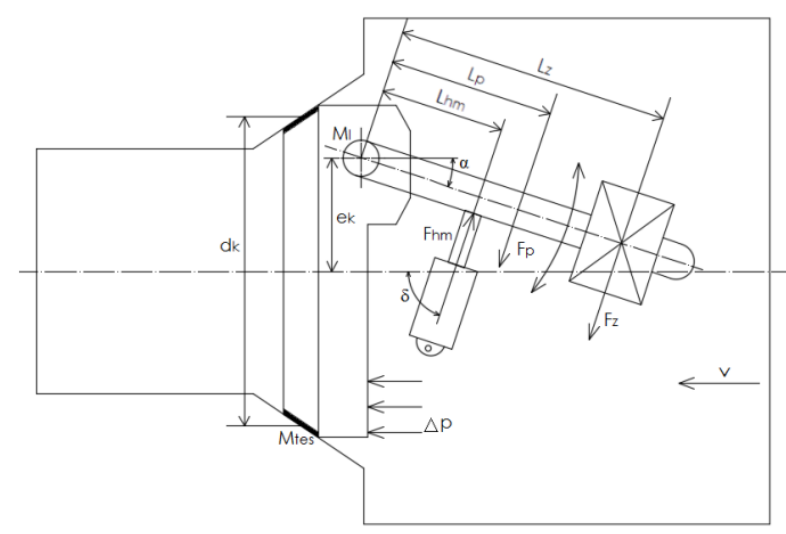

Fig. 3. Scheme for calculating butterfly valve

When opening valves is required to overcome the frictional moment on gasket [2]

$$
M_{\text {tes }}=\frac{(2,4 \cdot \Delta p+1,6) \cdot d_{k}^{2}}{1000}
$$

where $\Delta p$ is pressure differnece and $d_{k}$ is diameter of valve plate.

Moment generated by friction in bearings

$$
M_{t l}=F_{l} \cdot \frac{d_{l}}{2}
$$

where $d_{l}$ is a diameter of bearings and $F_{l}$ is the force acting on bearings. The bearings are placed on both sides of the control pin. The force from the weight of plate is equally divided on both bearings. On the one bearing is still a force from the weight of control device (lever and mass weight)

$$
\begin{gathered}
F_{l}=F_{l 1}+F_{l 2} \\
F_{l}=\left(\frac{1}{2} \cdot m_{t} \cdot g+\frac{1}{2} \cdot m_{t} \cdot g+m_{o v} \cdot g,\right) \cdot f_{l} \\
F_{l}=\left(m_{t}+m_{o v}\right) \cdot g \cdot f_{l},
\end{gathered}
$$

where $m_{t}$ is the weight of plate, $m_{o v}$ is the weight of control device, $g$ is gravity acceleration and $f_{l}$ is coefficient of friction.

Moment of friction in seals

$$
M_{t u}=F_{u} \cdot \frac{d_{u}}{2} .
$$

where $d_{u}$ is diameter of seals and $F_{u}$ is the force acting on seals

$$
F_{u}=\frac{\pi \cdot d_{u} \cdot l_{u} \cdot p \cdot f_{u}}{2}
$$


where $l_{u}$ is length of seals, $p$ is pressure of working medium and $f_{u}$ coefficient of friction of seals (depends on the material of seal). In calculation is for simplification considered an inner cylindrical surface of seals. Manufacturers of closure elements usually to calculate the moment on seals used experimentally observed empirical equation, which is under their production know-how.

Moment by the weight of lever

$$
M_{p}=F_{p} \cdot L_{p},
$$

where $L_{p}$ is length of centre of gravity lever and $F_{p}$ is the force acting in this centre of gravity

$$
F_{p}=m_{p} \cdot g \cdot \cos \alpha
$$

where $m_{p}$ is weight of lever and $\alpha$ is the angle of rotation lever (and mass weight).

Moment by the mass weight

$$
M_{z}=F_{z} \cdot L_{z},
$$

where $L_{z}$ is length of centre of gravity mass weight (this value can be changed) and $F_{z}$ is the force acting in centre of gravity mass weight

$$
F_{z}=m_{z} \cdot g \cdot \cos \alpha,
$$

where $m_{z}$ is the amount of mass weight.

The total moment on the lever and mass weight

$$
M_{z c}=M_{p}+M_{z}
$$

Finally, hydraulic moment from the flowing medium. In the case that the valve is completely closed $(\beta=0)$, this is a static moment

$$
M_{t s}=\pi \cdot \frac{d_{k}^{2}}{4} \cdot \Delta p \cdot e_{k}
$$

where $e_{k}$ is eccentricity, distance from the axis of pin. When the valve is opened, depending on the opening acting hydrodynamic moment [3]

$$
M_{t d}=k \cdot \frac{d_{k}^{3}}{12} \cdot \frac{\gamma \cdot v^{2}}{20 \cdot g} \cdot \frac{9,81}{100},
$$

where $k$ is resistance coefficient, $\gamma\left[\mathrm{kg} \cdot \mathrm{m}^{-4} \cdot \mathrm{s}^{2}\right]$ includes the density of the flowing medium and $\rho=\gamma / g$ [4], $v$ is velocity of flowing medium. If we are substituting in basic units and substitute in formula the density $\rho$ of the flowing medium, we can modify the equation (12) to

$$
M_{t d}=k \cdot \frac{d_{k}^{3}}{12} \cdot \frac{\rho \cdot v^{2}}{20} \cdot 9,81
$$

Resistance coefficient includes the effect of opening the valve. Its value can be determined experimentally, or by using mathematical models. In the model calculation were considered the value of the resistance coefficient $k$ from the Fig. 4 [4].
Summing up all these moments we get the minimum required moment of hydraulic motor

$$
M_{h m}=M_{t e s}+M_{t l}+M_{t u}+M_{z c}+M_{t} .
$$

Minimum required force of hydraulic motor (not tilted into the axis of the hydraulic motor)

$$
F_{h m}=\frac{M_{h m}}{L_{h m}},
$$

where $L_{h m}$ is the attaching distance of hydraulic motor to the lever. After tilting the forces to the axis of the hydraulic motor

$$
F_{h m s}=\frac{\cos \delta \cdot F_{h m}}{\cos \alpha} .
$$

where $\delta$ is the tilt angle of the hydraulic motor to the axis of valve (axis of flow) and $\alpha$ is the tilt angle of lever and mass weight to the axis of valve. Based on the resulting force $F_{h m s}$, it is necessary to select a higher working force of hydraulic motor.

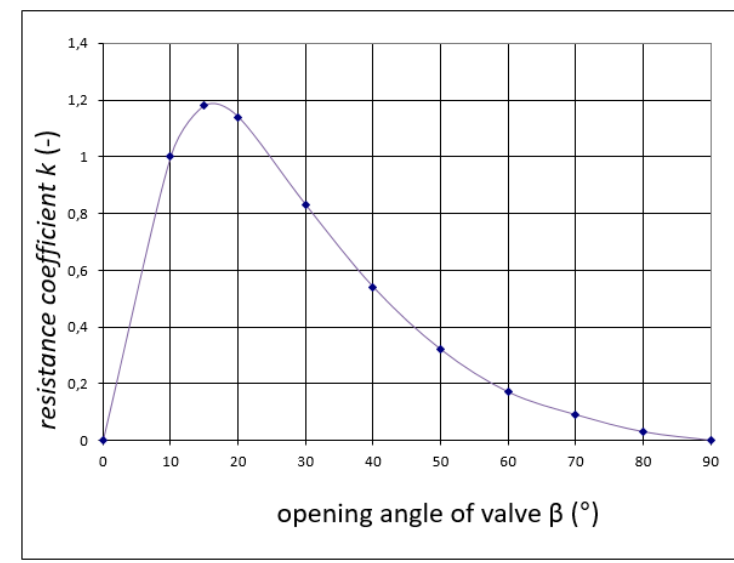

Fig. 4. Graph of the resistance coefficient depending on the opening of valve

\section{Examples of calculation}

As an example of the design of butterfly valve and control hydraulic motor, we can mention a model case. The parameters required for the calculation are shown in Tab.1.

Tab. 1. Parameters required for the example calculation

\begin{tabular}{|l|c|}
\hline \multicolumn{1}{|c|}{ Given parameters } & Value of parameter \\
\hline Diameter of valve & $d_{k}=1000 \mathrm{~mm}$ \\
\hline Eccentricity of valve & $e_{k}=200 \mathrm{~mm}$ \\
\hline Pressure drop & $\Delta p=0,2 \mathrm{MPa}$ \\
\hline Opening angle of valve & $\beta=0 \div 90^{\circ}$ \\
\hline Length of mass weight & $L_{z}=800 \mathrm{~mm}$ \\
\hline Mass of the weights & $m_{z}=210 \mathrm{~kg}$ \\
\hline Length of lever & $L_{p}=450 \mathrm{~mm}$ \\
\hline Mass of lever & $m_{p}=70 \mathrm{~kg}$ \\
\hline Mass of plate & $m_{t}=800 \mathrm{~kg}$ \\
\hline Mass of control & $m_{o v}=300 \mathrm{~kg}$ \\
\hline Length of hydraulic motor & $L_{h m}=300 \mathrm{~mm}$ \\
\hline
\end{tabular}




\begin{tabular}{|l|c|}
\hline Diameter of seals & $d_{u}=70 \mathrm{~mm}$ \\
\hline Length of seals & $l_{u}=80 \mathrm{~mm}$ \\
\hline $\begin{array}{l}\text { Coefficient of friction of } \\
\text { seals }\end{array}$ & $f_{u}=0,2$ \\
\hline Diameter of bearings & $d_{l}=70 \mathrm{~mm}$ \\
\hline $\begin{array}{l}\text { Friction coefficient in } \\
\text { bearings }\end{array}$ & $f_{l}=0,16$ \\
\hline
\end{tabular}

Working medium is water, the flow velocity is considered $v=1 \mathrm{~m} \cdot \mathrm{s}^{-1}$. Orientation of flow direction corresponding to Fig.3. Realistically, there may be two basic states. The first case when the valve is closed and to its opening occurs due to moment from control hydraulic motor. This moment was determined based on the equation (14) and the required force of hydraulic motor from equation (16).

This force was for our model case $F_{h m s}=117545,2 \mathrm{~N}$, on the basis of that was selected a greater force of the hydraulic motor $125000 \mathrm{~N}$. For this force would be designed hydraulic motor, when at the working pressure in the hydraulic circuit $12 \mathrm{MPa}$, and the piston diameter of the hydraulic motor would be $D=115 \mathrm{~mm}$. The sizes of moments are shown in Fig.5. Where $M_{n}$ is size of moment required to opening valve and $M_{h m}$ is the size of moment from our designed hydraulic motor.

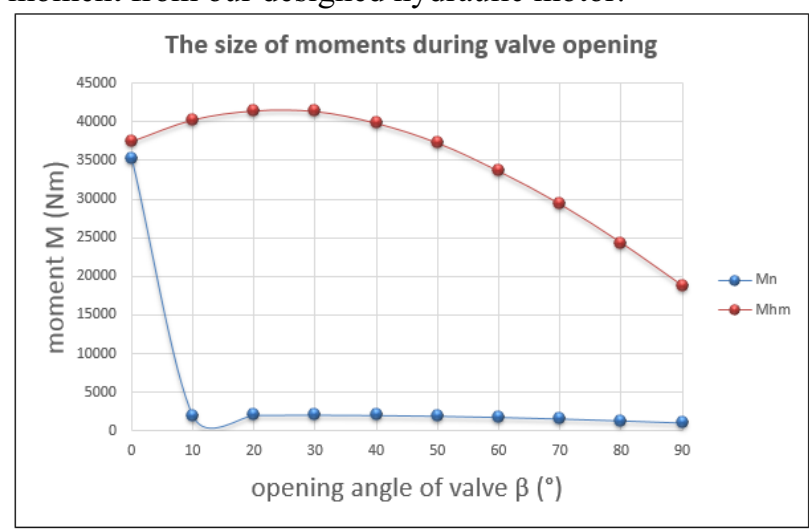

Fig. 5. The size of moments during the opening of valve

Tab. 2 shows the maximum values of the individual components of moments, for our model case.

Tab. 2. The maximum values of the individual components of moments

\begin{tabular}{|l|c|}
\hline \multicolumn{1}{|c|}{$\begin{array}{c}\text { Individual components of } \\
\text { moments }\end{array}$} & Size of moments \\
\hline Moment on gasket & $M_{t e s}=2080 \mathrm{~N} \cdot \mathrm{m}$ \\
\hline $\begin{array}{l}\text { Moment from friction in } \\
\text { bearings }\end{array}$ & $M_{t l}=60,42 \mathrm{~N} \cdot \mathrm{m}$ \\
\hline Moment of friction in seals & $M_{t u}=12,31 \mathrm{~N} \cdot \mathrm{m}$ \\
\hline $\begin{array}{l}\text { Moment on the lever and } \\
\text { mass weight }\end{array}$ & $M_{z c}=1694,89 \mathrm{~N} \cdot \mathrm{m}$ \\
\hline $\begin{array}{l}\text { Static moment from the } \\
\text { flowing medium }\end{array}$ & $M_{t s}=31415,9 \mathrm{~N} \cdot \mathrm{m}$ \\
\hline $\begin{array}{l}\text { Dynamic moment from the } \\
\text { flowing medium }\end{array}$ & $M_{t d}=46,59 \mathrm{~N} \cdot \mathrm{m}$ \\
\hline
\end{tabular}

In the case of closing valve, it is necessary to obtain a closing moment $M_{z}$, which must be higher than the moment of passive resistances $M_{n}$. In this case, the flowing medium helps with closing of valve and the equation (14) is changing to

$$
M_{z c}+M_{t} \geq M_{t e s}+M_{t l}+M_{t u}+M_{h m p}
$$

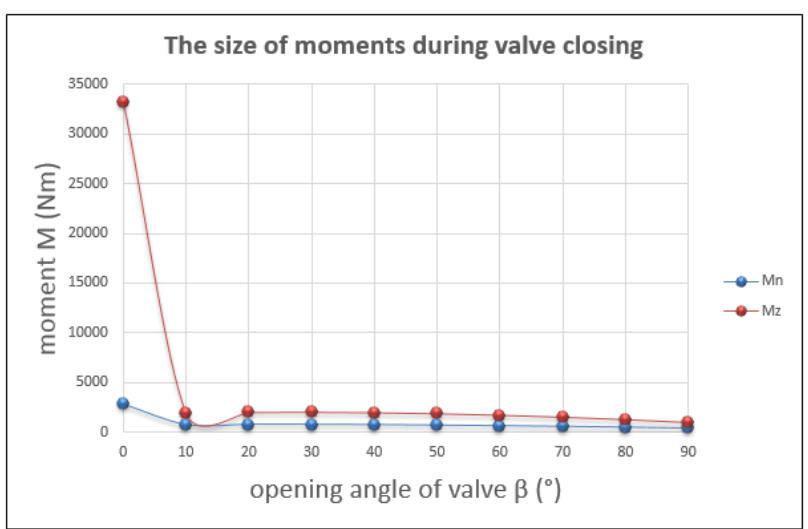

Fig. 6. The size of moments during the closing of valve Where $M_{h m p}$ is moment from passive resistances of hydraulic motor, its size depends on the type of hydraulic motor and control of hydraulic circuit. The courses of moments when the valve is closing are shown for model case in Fig.6.

\section{Conclusion}

In this paper was presented a possible procedure for the design of butterfly valves and their controls. The manufacturers of closure elements in their design often use empirical equations which determined experimentally. Realization of experimental measurements primarily for large diameter of valves is relatively complicated and expensive. For a description of the behavior of valve is possible based from the theory of hydraulic similarity. From this perspective, it seems like the ideal solution to use the numerical simulations. In the future we plan to deal with the issue of using CFD modeling.

\section{Acknowledgements}

This work was supported by the project SP2016/70 of VŠB Technical University of Ostrava.

\section{References}

1- J. Ronček, Průmyslové armatury, (2002)

2- J. Melecký, Návrh pohonů pro uzavírací bezpečnostní klapku, (2013)

3- D.F. Gurevič, Raschet $i$ konstruirovanie truboprovodnoy armatury, (1966)

4- C. Keller, F. Salzmann, Luft-Modellversuche an Drosselklappen für Druckleitungen von Wasserkraftanlagen, (1936)

5- M. Nechleba, Vodní turbiny, jejich konstrukce a prislušenství, (1962)

6- J. Jablonská, M. Kozubková, Flow characteristics of control valve for different strokes, EPJ Web of Conferences. Vol. 114. EDP Sciences (2016) 